\title{
Airborne dust distributions over the Tibetan Plateau and surrounding areas derived from the first year of CALIPSO lidar observations
}

\author{
Z. Liu ${ }^{1}$, D. Liu ${ }^{2}$, J. Huang ${ }^{3}$, M. Vaughan ${ }^{4}$, I. Uno ${ }^{5}$, N. Sugimoto ${ }^{6}$, C. Kittaka ${ }^{7}$, C. Trepte ${ }^{4}$, Z. Wang ${ }^{2}$, C. Hostetler ${ }^{4}$, \\ and D. Winker ${ }^{4}$ \\ ${ }^{1}$ National Institute of Aerospace, Hampton, VA 23666, USA \\ ${ }^{2}$ University of Wyoming, Laramie, WY 82071, USA \\ ${ }^{3}$ Lanzhou University, Lanzhou, Gansu, China \\ ${ }^{4}$ NASA Langley Research Center, Hampton, VA 23681, USA \\ ${ }^{5}$ Kyushu University, Kasuga, Fukuoka, Japan \\ ${ }^{6}$ National Institute for Environmental Studies, Tsukuba, Ibaraki, Japan \\ ${ }^{7}$ Science Systems and Applications, Inc, Hampton, VA, USA
}

Received: 12 February 2008 - Published in Atmos. Chem. Phys. Discuss.: 25 March 2008

Revised: 24 June 2008 - Accepted: 21 July 2008 - Published: 29 August 2008

\begin{abstract}
Using an analysis of the first full year of CALIPSO lidar measurements, this paper derives unprecedented, altitude-resolved seasonal distributions of desert dust transported over the Tibetan Plateau (TP) and the surrounding areas. The CALIPSO lidar observations include numerous large dust plumes over the northern slope and eastern part of the TP, with the largest number of dust events occurring in the spring of 2007, and some layers being lofted to altitudes of $11-12 \mathrm{~km}$. Generation of the Tibetan airborne dusts appears to be largely associated with source regions to the north and on the eastern part of the plateau. Examination of the CALIPSO time history reveals an "airborne dust corridor" due to the eastward transport of dusts originating primarily in these source areas. This corridor extends from west to east and shows a seasonality largely modulated by the TP through its dynamical and thermal forcing on the atmospheric flows. On the southern side, desert dust particles originate predominately in Northwest India and Pakistan. The dust transport occurs primarily in dry seasons around the TP western and southern slopes and dust particles become mixed with local polluted aerosols. No significant amount of dust appears to be transported over the Himalayas. Extensive forward trajectory simulations are also conducted to confirm the dust transport pattern from the nearby sources observed by the CALIPSO lidar. Comparisons with the OMI and MODIS
\end{abstract}

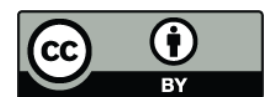

Correspondence to: Z. Liu (zhaoyan.liu-1@nasa.gov) measurements show the unique capability of the CALIPSO lidar to provide unambiguous, altitude-resolved dust measurements.

\section{Introduction}

The Tibetan Plateau (TP) is the highest and most extensive plateau in the world. It has an average elevation over $4500 \mathrm{~m}$ and covers most of the Tibet Autonomous Region and Qinghai Province in China. The plateau is surrounded by the Earth's highest mountains, including the Himalayas and the Pamir and Kunlun ranges, with the Taklimakan Desert to the north, the Gobi Desert to the northeast, and the deserts in Southwest Asia and Middle East to the west and southwest. Recent studies suggest that the climate in the TP region is changing. For example, surface temperature measurements (Liu and Chen, 2000) and ice core analyses (Thompson et al., 2003) show that the TP has been experiencing accelerated warming, especially in winter, during the past several decades. This warming trend is thought to be the major cause for the ablation of mountain glaciers on the TP (Thompson et al., 2003), which feed major Asian rivers such as the Yangtze, the Indus and the Ganges. If the glaciers in the TP continue to retreat, there will be major impacts on the hydrologic cycle and water availability to the populations of India and China (Ramanathan et al., 2007; Barnett et al., 2005).

Dust is a major component of the aerosol burden over the plateau (e.g., Zhang et al., 2001) and on the northern side of

Published by Copernicus Publications on behalf of the European Geosciences Union. 
the surrounding area, where the Taklimakan and Gobi deserts are located (e.g., Qian et al., 2002). Dust particles arising from the numerous surrounding sources can be transported to and stacked over the TP. On the southern side, dust transported from the Arabian Peninsula or generated on the Indian Subcontinent is often mixed with large concentrations of locally generated pollution aerosols (Middleton, 1986). The local pollution alone can enhance the solar heating of the low atmosphere by $\sim 50 \%$ (Ramanathan et al., 2007). Due to its particular orography and location, the TP can significantly influence the Asian climate through dynamical and thermal forcing (Wu et al., 2006). In this context, dust may play an important role. For example, model studies by Lau et al. (2006) show that the highly elevated surface air over the plateau may act as an "elevated heat pump" and alter the regional climate significantly through the absorption of solar radiation by dust coupled with black carbon emission from industrial areas in northern India. As a result, a tropospheric temperature anomaly may be induced in late spring and early summer over parts of northern India and Tibet, leading to an earlier onset and intensification of the Indian monsoon. In addition to the direct effects due to scattering and absorption, dust aerosols can also influence the earth's climate indirectly, through interactions with clouds that can alter the cloud physical and optical properties (e.g., Sassen, 2002; Zuberi et al., 2002). Dust aerosol can also undergo, over the course of transport, changes in mineralogical compositions (Jeong, 2008) and hygroscopic and heterogeneous reactions (Seinfeld et al., 2004). These processes can alter the dust physical and optical properties and hence change the dust radiative properties.

However, the effects of the Tibetan aerosol on the regional climate variability remain largely unknown, due partly to an insufficient number of observations over the plateau. Altitude-resolved observations are especially lacking. Most existing ground weather stations are located on the eastern part and the slopes of the western part of the TP (Huang et al., 2007). Passive satellite sensors, such as the Moderate Resolution Imaging Spectroradiometer (MODIS) and the Ozone Monitoring Instrument (OMI), etc., can provide measurements of aerosol column optical properties on a global scale. However, no information on the vertical distribution of aerosols can be obtained from these measurements. Aerosols, particularly dust and pollution, can exert a far greater influence on the surface and atmospheric energy budget than on the top of the atmosphere (TOA) radiation budget because of their light absorbing capacity (Seinfeld et al., 2004). Vertical distribution information is essential to accurately assess the radiative impact of aerosols on the Earth and its atmosphere. Therefore, additional observations of heightresolved aerosol distributions over a larger geographic region are required to obtain a more complete understanding of the climatological impact of the aerosol loading over the TP and the surrounding areas.
A global data set of altitude-resolved measurements of the Earth's atmosphere is now being acquired by the CloudAerosol Lidar with Orthogonal Polarization (CALIOP), which was launched in April 2006 onboard the CloudAerosol Lidar and Infrared Pathfinder Satellite Observations (CALIPSO) satellite (Winker et al., 2007). CALIOP's high resolution vertical profiling ability and accurate depolarization measurements make it a superb platform for the study of dust aerosols (Liu, D., et al., 2008; Liu, Z. et al., 2008). An initial analysis of dust observed by CALIOP in summer 2006 has shown that the occurrence frequency over the TP northern slope is significantly larger than that found by ground stations (Huang et al., 2007). In this paper we use the first year of CALIOP measurements (June 2006 through May 2007) to derive altitude-resolved, seasonally dependent distributions of dust over the TP and the nearby vicinity, and to illustrate patterns of dust transport up to and across the plateau. We also conduct a full season HYSPLIT simulation to study the contributions from the various nearby dust sources.

\section{CALIOP data and dust aerosol identification}

CALIOP version 1 data products are used in this study. The primary measurements made by CALIOP are three calibrated and geolocated lidar profiles - total attenuated backscatter at $532 \mathrm{~nm}$ and $1064 \mathrm{~nm}$, and the perpendicular polarization component of the backscatter at $532 \mathrm{~nm}$ (Hostetler et al., 2006). The attenuated backscatter is defined as

$\beta_{\lambda}^{\prime}(r)=\left[\beta_{\lambda, m}(r)+\beta_{\lambda, p}(r)\right] T_{\lambda}^{2}(r)=\frac{X_{\lambda}(r)}{C_{\lambda}}$,

where $\beta_{\lambda, m}(\mathrm{r})$ and $\beta_{\lambda, p}(\mathrm{r})$ are the backscatter coefficients due to, respectively, molecular scattering and particulate scattering at range $r$ and the laser wavelength $\lambda(1064 \mathrm{~nm}$ or $532 \mathrm{~nm}) . T_{\lambda}^{2}(\mathrm{r})$ is the two-way atmospheric transmittance, $X_{\lambda}(\mathrm{r})$ is the range-corrected lidar backscatter signal, and $C_{\lambda}$ is the calibration coefficient. Volume depolarization ratio (VDR) is computed directly from the ratio of the two polarization components of the attenuated backscatter at $532 \mathrm{~nm}$, using

$\delta(r)=\frac{\beta_{532, \perp}^{\prime}(r)}{\beta_{532, \|}^{\prime}(r)}=\frac{\beta_{532, m, \perp}(r)+\beta_{532, p, \perp}(r)}{\beta_{532, m, \|}(r)+\beta_{532, p, \|}(r)}$

(Cairo et al., 1999). In this equation and hereafter, the subscripts $\perp$ and $\|$ represent, respectively, the components of the backscatter signal polarized perpendicular and parallel to the polarization plane of the linearly polarized laser pulses. For this study, the CALIOP profiles are averaged to a $5 \mathrm{~km}$ horizontal resolution (15 laser pulses), and only the nighttime portion of the data is used. Due to the presence of strong solar radiation, the daytime data is noisier than the nighttime data, and thus needs substantially more averaging to achieve the same signal-to-noise ratio (SNR) as the nighttime data. 
The exclusion of daytime data should have only a small impact on the derived dust occurrence distributions. Although dust storms tend to occur preferentially during daytime, sedimentation times are not governed by a diurnal cycle, and thus the omission of daytime data should have little or no effect on the occurrence frequency of airborne dusts and the floating dust events studied in this paper.

In deriving the dust distributions reported here, we examine only cloud-free profiles. These profiles are identified using the $5 \mathrm{~km}$ cloud layer products produced by the CALIOP level 2 analyses (Vaughan et al., 2004). In this process, the discrimination between cloud and aerosol layers is accomplished primarily using altitude-dependent, multiple-dimensional probability density functions (PDFs) of layer-averaged $532 \mathrm{~nm}$ attenuated backscatter coefficients and the $1064 \mathrm{~nm} / 532 \mathrm{~nm}$ attenuated backscatter ratio (Liu et al., 2004). The discrimination approach is essentially based on the fact that clouds usually have larger $532 \mathrm{~nm}$ attenuated backscatter and $1064 \mathrm{~nm} / 532 \mathrm{~nm}$ backscatter ratio than aerosols. For layers initially classified as aerosols, an additional test is conducted using VDR with a latitude dependent threshold that was pre-defined based on the CALIOP measurements. The VDR for dust aerosols is generally smaller than 0.35, based on the CALIOP measurement (refer to Fig. 1). For this reason, the VDR threshold is fixed at 0.35 from the surface to $3 \mathrm{~km}$ in the geographic regions studied in this paper. Because the VDR decreases as the dust concentration decreases (refer to Eq. 2), and because the dust concentration is generally smaller at higher altitudes than at lower altitudes, the VDR threshold decreases with increasing altitude above $3 \mathrm{~km}$ (to 0.2 above $5 \mathrm{~km}$ ). This secondary test significantly reduces possible misclassifications of some ice clouds as aerosols, because ice clouds typically have larger depolarization ratios than those that are characteristic of dust aerosols.

The presence of overlying clouds makes the dust measurement difficult. Over the tropical and subtropical regions during Asian monsoon seasons, the cloud coverage is very high and consequently it is hard to obtain sufficient cloud-free profiles to derive reliable dust distributions (refer to Fig. $4 \mathrm{~b}$ in Sect. 3.2). However, over the TP and surrounding areas, sufficient cloud-free profiles can be obtained to derive reliable dust distributions.

The presence of dust at a given altitude range of each $5 \mathrm{~km}$ profile is detected using the VDR that is averaged over the corresponding altitude range based on

$$
\bar{\delta}=\frac{\sum_{r=r_{\text {base }}}^{r_{\text {top }}} X_{532, \perp}(r)}{\sum_{r=r_{\text {base }}} X_{532, \|}(r)},
$$

where $r_{\text {top }}$ and $r_{\text {base }}$ are the top and base of the corresponding altitude range. The depolarization ratio of dust is high due to
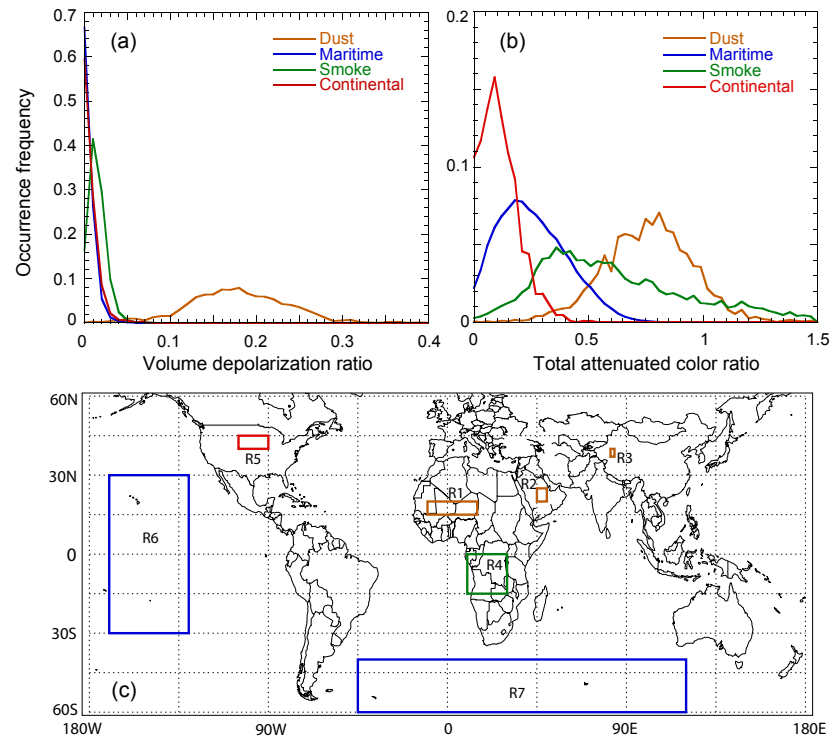

Fig. 1 Histogram distributions of volume depolarization ratio (a) and total attenuated color ratio (b) averaged between $1 \mathrm{~km}$ and $2 \mathrm{~km}$ above ground level (AGL) for four major aerosol types derived from CALIOP measurements acquired at seven selected geographic regions as defined by the squares in (c) where each aerosol type is typically dominant. These geographic regions include: $10^{\circ} \mathrm{W}-$ $15^{\circ} \mathrm{E}$ and $15^{\circ} \mathrm{N}-20^{\circ} \mathrm{N}$ (indicated by R1) in North Africa, $45^{\circ} \mathrm{E}-$ $50^{\circ} \mathrm{E}$ and $20^{\circ} \mathrm{N}-25^{\circ} \mathrm{N}$ (R2) in Arabian Peninsula, and $82^{\circ} \mathrm{E}-84^{\circ} \mathrm{E}$ and $37^{\circ} \mathrm{N}-40^{\circ} \mathrm{N}$ (R3) in Taklimakan desert (desert dust aerosol), $10^{\circ} \mathrm{E}-30^{\circ} \mathrm{E}$ and $15^{\circ} \mathrm{S}-0^{\circ}$ (R4) in Central Africa (biomass burning aerosol), $105^{\circ} \mathrm{W}-90^{\circ} \mathrm{W}$ and $40^{\circ} \mathrm{N}-45^{\circ} \mathrm{N}$ (R5) in North America (continental aerosol), $170^{\circ} \mathrm{W}-130^{\circ} \mathrm{W}$ and $30^{\circ} \mathrm{S}-30^{\circ} \mathrm{N}$ (R6) in Pacific Ocean and $45^{\circ} \mathrm{W}-120^{\circ} \mathrm{E}$ and $60^{\circ} \mathrm{S}-40^{\circ} \mathrm{S}$ (R7) in South Atlantic Ocean and South Indian Ocean (and maritime aerosol). The time period of the CALIOP data used in deriving the histogram distributions is December 2006-February 2007 (wintertime) for the continental aerosol type and June 2006-August 2006 (summertime) for the dust, maritime and biomass burning aerosol types.

the nonsphericity and relatively large size of the dust particles (McNeil and Carswell, 1975; Kobayashi et al., 1983), whereas this ratio is low (close to zero) for other aerosol types. This is evident from the histogram of distributions presented in Fig. 1a for different aerosol types. These distributions were derived from CALIOP measurements acquired over selected geographic regions, as defined by the rectangular boxes in Fig. 1c, where each aerosol type is typically dominant (Liu, D. et al., 2008). It is seen that the VDR distribution for the dust aerosols is centered at a large value of $\sim 0.17$. On the other hand, the maritime and continental aerosols have a VDR distribution peaked at zero because these types of aerosols are mostly composed of spherical particles. Biomass burning aerosols contain non-spherical small size black-carbon particles, and thus this distribution has a nonzero peak at a small value of $\sim 0.02$. We note, however, that the VDR for optically thin dust layers can 

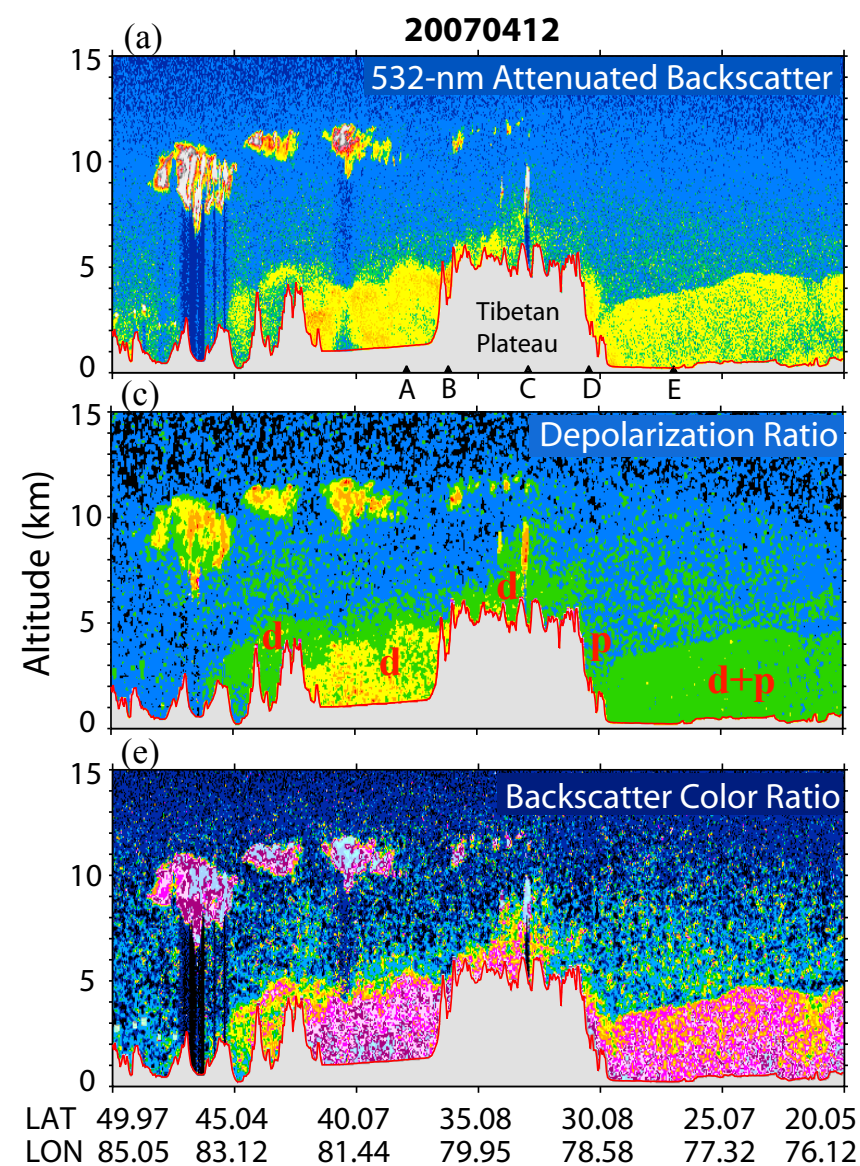
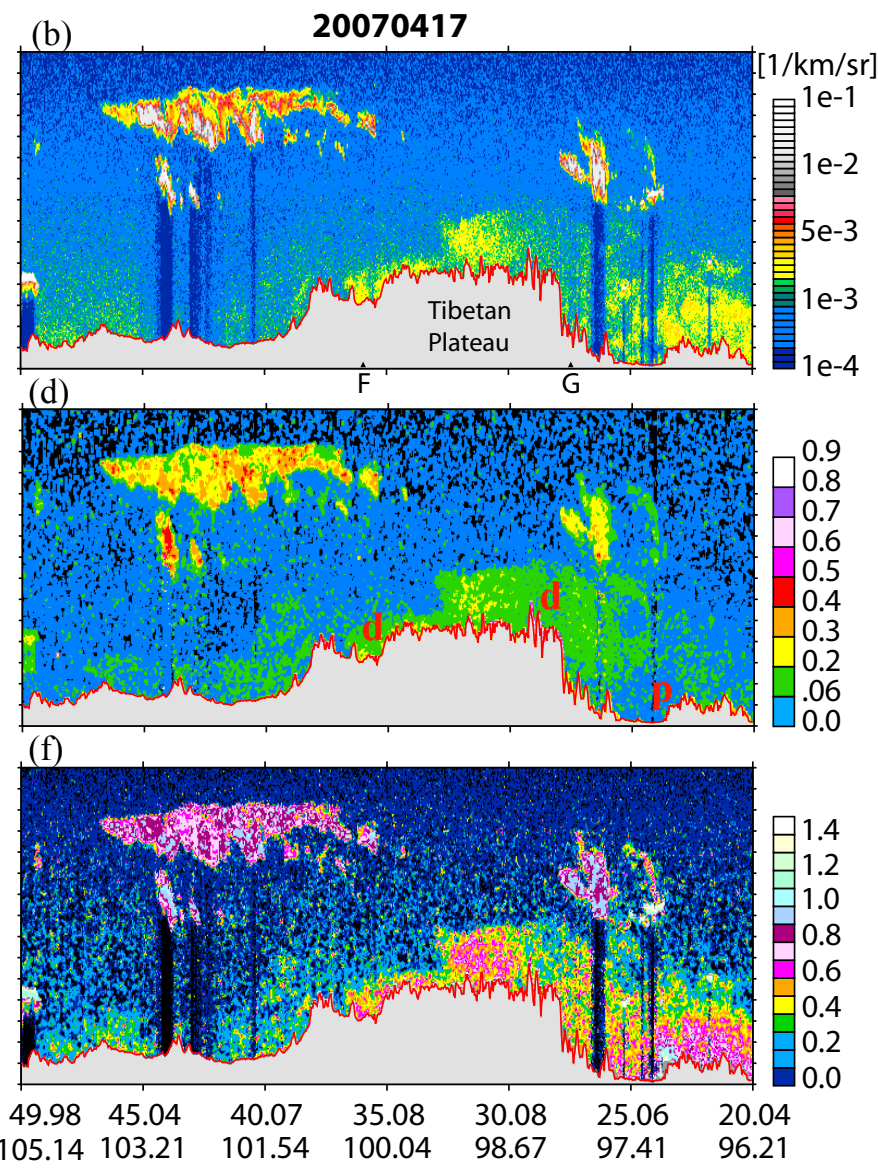

Fig. 2 Examples of dust transport to and across the Tibetan Plateau measured by CALIOP on 12 and 17 April 2007; (a) and (b) show 532-nm attenuated backscatter; (c) and (d) show volume depolarization ratios; and (e) and (f) present the 1064-nm/532-nm attenuated backscatter color ratio. In (a) and (b), the red-gray-white colored high features are clouds and the green-yellow-orange colored features are aerosols. The red line in indicates the surface. Red characters "d", "p" and "d+p" in (c) and (d) represent "dust", "polluted", and "dust+polluted" dominated aerosols, respectively. Letters A-F indicate the locations where the back trajectories shown in Fig. 3 are initiated.

also be small, because in these cases the molecular scattering $\left(\delta_{\text {molecular }} \simeq 0.0036\right)$ dominates total return signals (refer to Eq. 2). We identify dust by defining a VDR threshold value such that dust signals are detected as often as possible while simultaneously minimizing false positives due to other aerosol species. A threshold of 0.06 was selected based on the histogram distributions shown in Fig. 1a, which allows the detection of most of airborne dusts ( $98 \%)$ and rejection of most of other types of aerosols ( $\sim 98 \%)$. At an altitude of $1 \mathrm{~km}$, this threshold value corresponds to a horizontal visibility distance in excess of $60 \mathrm{~km}$ (refer to Appendix A). Thus, all normally defined dust events, including dust storms (visibility $<1 \mathrm{~km}$ ), blowing dust $(1-10 \mathrm{~km})$, and floating dust (around $10 \mathrm{~km}$ or less) (e.g., Qian et al., 2002; Shao and Dong, 2006), as well as some soil dusts, fly ashes, etc., should be captured.

Histograms of the total attenuated color ratio (ACR) for different aerosol types derived in the selected geographic regions are presented in Fig. 1b. ACR is derived from the attenuated backscatter ratio (ABR), defined as

$$
\begin{aligned}
& \chi^{\prime}(r)=\frac{\beta_{1064}^{\prime}(r)}{\beta_{532}^{\prime}(r)}= \\
& \frac{\left[\beta_{1064, m}(r)+\beta_{1064, p}(r)\right] \exp \left\{-2 \int_{0}^{r}\left[\alpha_{1064, p}\left(r^{\prime}\right)+\alpha_{1064, m}\left(r^{\prime}\right)\right] d r^{\prime}\right\}}{\left[\beta_{532, m}(r)+\beta_{532, p}(r)\right] \exp \left\{-2 \int_{0}^{r}\left[\alpha_{532, p}\left(r^{\prime}\right)+\alpha_{532, m}\left(r^{\prime}\right)\right] d r^{\prime}\right\}} .
\end{aligned}
$$

The values in Fig. 1b represent data averaged over the 1$2 \mathrm{~km}$ altitude range using

$$
\mathrm{ACR}=\overline{\chi^{\prime}}=\frac{\sum_{\mathrm{r}=\mathrm{r}_{\text {base }}}^{\mathrm{r}_{\text {top }}} X_{1064}(\mathrm{r}) / \mathrm{C}_{1064}}{\sum_{\mathrm{r}=\mathrm{r}_{\text {base }}}^{\mathrm{r}_{\text {top }}} X_{532}(\mathrm{r}) / \mathrm{C}_{532}} .
$$

It is seen that, compared with other aerosol types, dust has larger ACR values, peaking at $\sim 0.8$. These larger values are due to the larger sizes of dust particles. For smoke aerosol, the particulate backscatter color ratio, $\beta_{1064, p}(r) / \beta_{532, p}(r)$, is normally small, and the distribution of the ACR derived from the CALIOP measurements for 


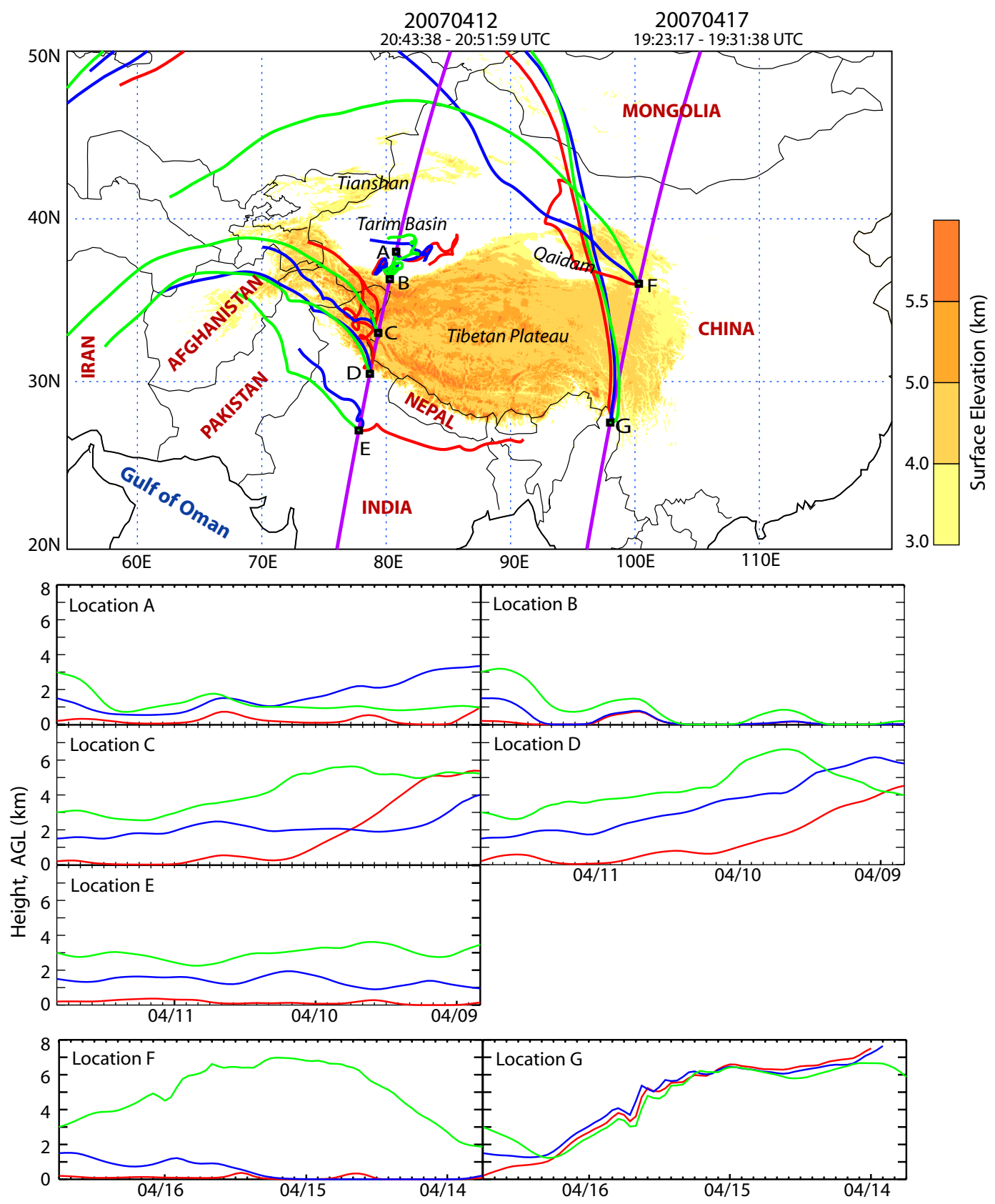

Fig. 3 Ground tracks of the CALIPSO orbits for the two examples shown in Fig. 1, and three-day back trajectories from HYSPLIT. The back trajectories originated at heights above the ground level of $0.2 \mathrm{~km}$ (red), $1.5 \mathrm{~km}$ (blue) and $3.0 \mathrm{~km}$ (green) at 20:00 UTC for 2007-04-12 and 19:00 UTC for 17 April 2007. Filled color contours in depict the plateau where the surface elevation is greater than 3, 4, and 5 and 5.5 km.

this type aerosol is seen to peak at $\sim 0.35$. However, the ACR for dense smokes can be large, due to the large wavelength dependence of the extinction. Observations have shown that smoke extinction at $532 \mathrm{~nm}$ is much larger than at $1064 \mathrm{~nm}$ (2.5-5 times; e.g., Pueschel and Livingston, 1990). When measuring dense smoke layers, the range-dependent reduction in lidar signals due to attenuation (the exponential terms in Eq. 4) occurs much faster at $532 \mathrm{~nm}$ than at $1064 \mathrm{~nm}$. As a result, the ACR will grow quickly, resulting in a large layer- averaged ACR. This fact is responsible for the long tail of large ACR values in the smoke distribution shown in Fig. 1b.

\section{Results and discussions}

\subsection{Dust transport examples}

Figure 2 presents two cases of dust transport up to and across the TP measured by CALIOP on 12 and 17 April 2007. The 
CALIPSO ground-tracks (purple lines) for the two cases, along with three-day back trajectories (red, blue, and green lines) at selected locations (A-G) along the track are presented in Fig. 3. The 12 April 2007 track passes over the western part of the TP (depicted by the color filled contour) and the 17 April 2007 track crosses the eastern part. The three-day back trajectories were computed using the NOAA HYSPLIT model (Draxler and Hess, 2004), and initialized at altitudes of $0.2 \mathrm{~km}$ (red), $1.5 \mathrm{~km}$ (blue) and $3.0 \mathrm{~km}$ (green) above ground level (AGL) at 20:00 UTC for 12 April 2007 and 19:00 UTC for 17 April 2007.

Attenuated backscatter coefficients measured at $532 \mathrm{~nm}$ by CALIOP are shown in Fig. $2 \mathrm{a}$ and b. Clouds typically have larger backscatter coefficients than aerosols (e.g., Hess et al., 1998; Liu et al., 2004). The red-gray-white colored features in Fig. 2a and b are clouds, and green-yellow-orange colored features are aerosols. VDR measurements are presented in Fig. $2 \mathrm{c}$ and $\mathrm{d}$, and the attenuated backscatter ratio (i.e., as in Eq. 4) is shown in Fig. 2e and f. As shown in Fig. 1, the dust aerosols have a large VDR value due to nonsphericity, while they also have a large color ratio due to their relatively large particle size. On the other hand, the other types of aerosols have small VDR values. Because dust particles are relatively large when compared to other aerosol species, and because the spectral dependence of their extinction coefficients is relatively small at the CALIOP wavelengths, dusts are typically characterized by moderately large, vertically uniform ACR profiles. Aerosols consisting of smaller particles will typically have smaller ACR values. Furthermore, if the extinction at $532 \mathrm{~nm}$ is significantly larger than at $1064 \mathrm{~nm}$, as is the case for smokes and pollution aerosols containing sizeable amounts of black carbon, the ACR will not be vertically uniform, but instead will be an increasing function of penetration into layer. Based on this combination of information contained in the three CALIOP measurements (the $532 \mathrm{~nm}$ attenuated backscatter, depolarization ratio, and total attenuated color ratio), we have manually identified regions containing dust aerosols (d), polluted aerosols (p) and their mixture $(d+p)$ (see Fig. 1c and d). The general rules used in these classifications are as follows: if VDR is high, the layer is dust dominated; if VDR is low and ACR is high, the layer is pollution dominated; and, if VDR is medium and ACR is high, the layer should be a mixture of dust and pollution (and possibly with other types of aerosols). However, optically thin smoke layers are difficult to identify based solely on the VDR and ACR measurements, because these measurements are not distinct from maritime and continental aerosols, as shown in Fig. 1.

For both cases shown in Fig. 2, airborne dusts were observed by CALIOP over the TP. For the 12 April 2007 case, dust was observed along the track from the Tianshan Mountains in the north, through the Tarim Basin area, and southward over the TP and into India. The densest plume appears over the Tarim Basin, with its top reaching $\sim 5 \mathrm{~km}$. The vertical structure is consistent with previous simulations (Uno et al., 2005). The back trajectories indicate that the airborne dusts over the Tarim area (location A) and on the northern slope (location B) of the TP are associated with dust activities in the Tarim Basin where ground stations recorded dust events. The meteorological analysis based on the Weather Research and Forecasting (WRF) model simulation shows that dust storms can be generated in the Tarim Basin during this time period, and that the plumes will remain trapped largely in the basin, consistent with the CALIOP measurement. On the Indian side (location E), the dust appears to be transported from one of many major dust sources in northern India, Pakistan and/or Afghanistan (Middleton, 1986). However, these dust particles can be mixed with locally generated pollution aerosols, soil dusts, fly ashes, etc. The $0.2 \mathrm{~km}$ back trajectory indicates that the air mass in the lower part of the aerosol plume is likely transported from northeastern India. A very dense aerosol plume is seen lofted over the TP southwestern slope (location D). Its VDR value is low, suggesting that the plume is dominated by polluted aerosol, though the back trajectories show a possibility of air parcel transport from Iran and/or Afghanistan, which may account for the relatively high ACR. Pollution aerosols, generally mixed with dust, are frequently observed by CALIOP over northern India and the southern and western slopes of the TP (Ramanathan et al., 2007). Over the plateau, the scattering intensity of the dust is relatively weak (Fig. 2a), but the dust particles appear to be lofted to an altitude of $\sim 10 \mathrm{~km}$ (Fig. 2c). Note that there are small scale clouds embedded in the dust being transported over the TP. The back trajectories (Fig. 3) indicate that the dust over the TP for location $\mathrm{C}$ may originate from sources west of the TP and/or be generated on the plateau itself. Airborne dusts on the TP can be generated both locally and remotely (Zhang et al., 2001).

The 17 April 2007 case is an example of dust being generated on and transported across the plateau and into Southeast Asia. As seen in Fig. 2d, there is a large dust plume covering much of the plateau along the lidar track, extending from $\sim 46^{\circ} \mathrm{N}$ into Myanmar to the south, where the plume becomes optically thinner and appears to become mixed with local pollution aerosols. Back trajectories (Fig. 3) suggest that this plume originated in the Qaidam Basin, on the northeastern TP, where dust storms were recorded on 16 April 2007 by ground stations situated in the basin and the area around location F. Based on ground station records recorded every three hours, this dust event was initially observed at 06:00 UTC, and lasted until 15:00 UTC. The ground wind speed over the area was between $7-12 \mathrm{~m} / \mathrm{s}$, which exceeds the wind speed threshold for dust emission over the area (Kurosaki and Mikami, 2007). The back trajectories for locations $\mathrm{F}$ and $\mathrm{G}$ along the CALIPSO track confirm the origin of the dust plume in the Qaidam Basin area. At location G, the dust plume extends to $\sim 5 \mathrm{~km}$ AGL. The back trajectories originated at three heights $(0.2,1.5$ and $3.0 \mathrm{~km}, \mathrm{AGL})$ all pass over the eastern Qaidam. At location F, the densest part of the dust plume extends to $\sim 1.5 \mathrm{~km}$ above the ground. 


\section{CALIOP Frequency of Dust Aerosol Occurrence}

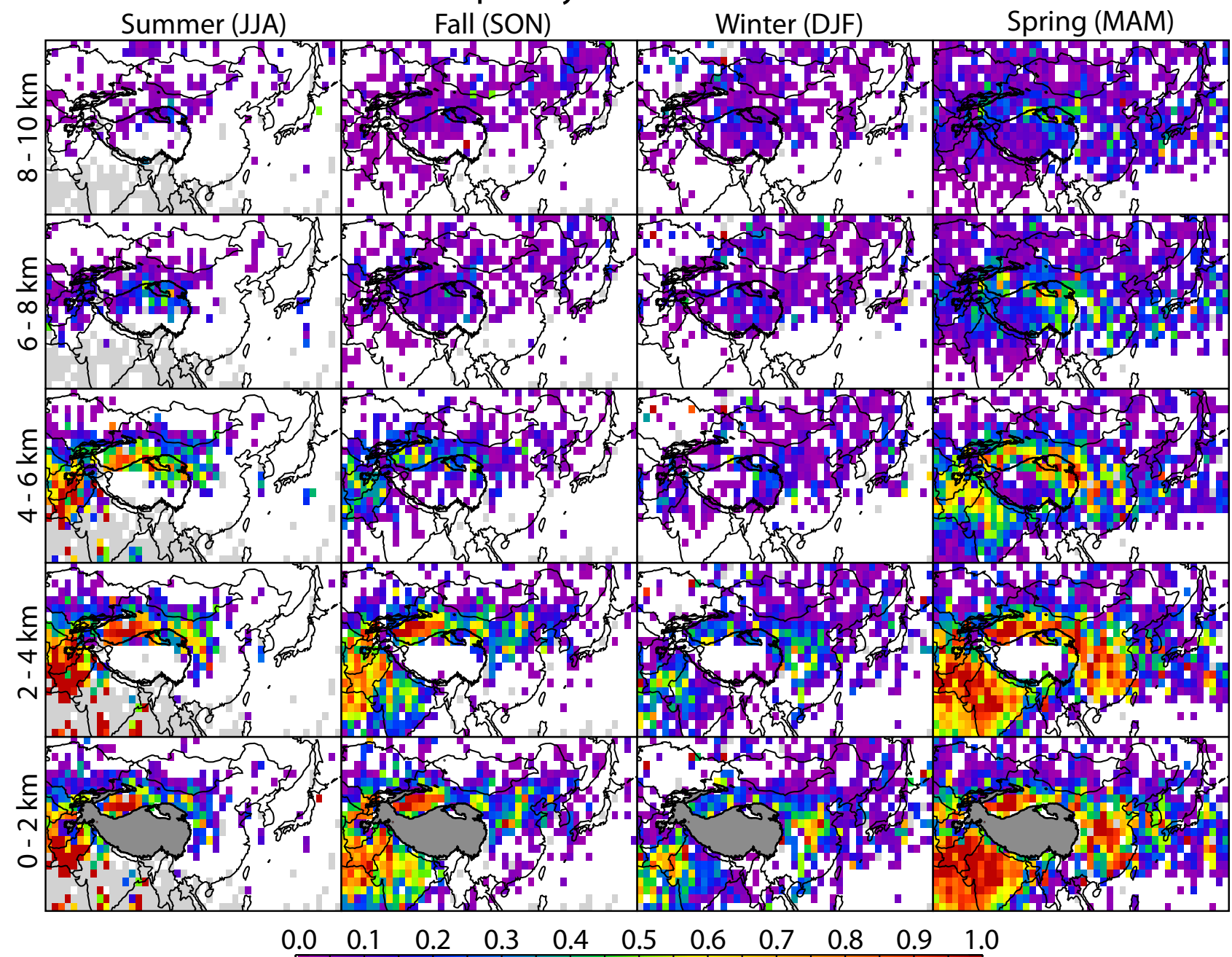

(a)

Number of Cloud Free Profiles

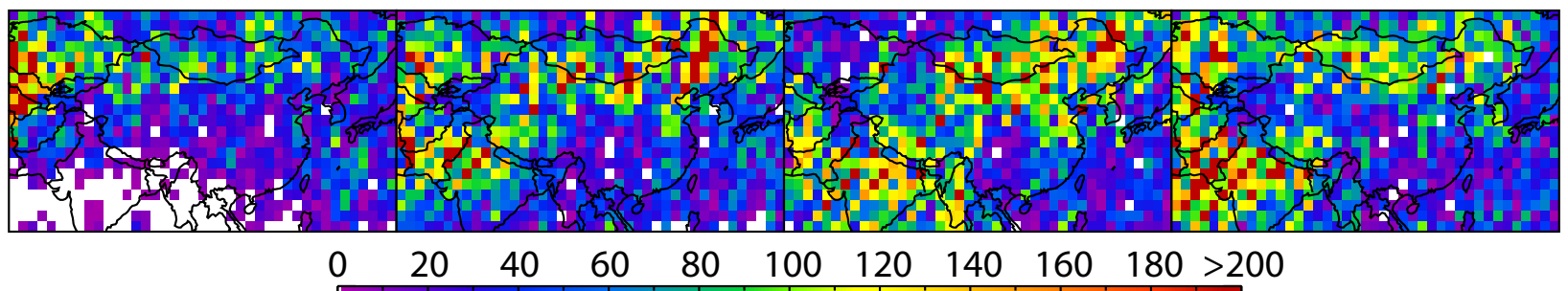

(b)

Fig. 4 (a) Occurrence distributions of airborne dusts over the Tibetan Plateau and the surrounding areas for five altitude ranges (0.0-2.0, 2.04.0, 4.0-6.0, 6.0-8.0 and 8.0-10.0 km, AMSL) derived from the first year CALIOP measurement. The dark gray regions in the 0.0-2.0 km panels and black contours in the other panels indicate the plateau, where the surface elevation is higher than $3 \mathrm{~km}$. Light gray pixels represent data points where no cloud free profiles were found. Altitudes are registered with respect to mean sea level. (b) Number distributions of cloud-free profiles. The grid resolution is $2^{\circ}$ in longitude by $2^{\circ}$ in latitude.

\subsection{Dust distributions}

Frequency distributions of airborne dusts over the TP and surrounding vicinity for five altitude ranges (0.0-2.0,
$2.0-4.0,4.0-6.0,6.0-8.0$ and $8.0-10.0 \mathrm{~km}$ above man sea level - AMSL), derived from the first year CALIOP measurement (June 2006 through May 2007), are presented in Fig. 4a. The frequency of dust aerosol occurrence, $f_{\text {occurrence, }}$ 
for a $2 \times 2$ degree pixel in a given altitude range is defined as the ratio of the number of dusty profiles $\left(N_{\text {dusty }}\right.$; VDR $>6 \%$ and cloud free) and the total number of cloud free profiles $\left(N_{\text {cloud-free }}\right)$ within the pixel; i.e.,

$f_{\text {occurrence }}=\frac{N_{\text {dusty }}}{N_{\text {cloud free }}}$.

To provide a closer look into the vertical distribution, Fig. 5 presents profiles of ABR (upper panels) and VDR (lower panels) at five selected locations in, respectively, the Ganganagar desert in the Thar desert area in Pakistan $\left(29.4^{\circ} \mathrm{N}, 71.7^{\circ} \mathrm{E}\right)$, the Taklimakan desert in west China $\left(38.5^{\circ} \mathrm{N}, 83.5^{\circ} \mathrm{E}\right)$, the Gobi desert in central North China $\left(40.4^{\circ} \mathrm{N}, 102.0^{\circ} \mathrm{E}\right)$, the Qaidam Basin on the northeastern TP $\left(37.0^{\circ} \mathrm{N}, 94.0^{\circ} \mathrm{E}\right)$ and in Central China $\left(34.0^{\circ} \mathrm{N}, 110.0^{\circ} \mathrm{E}\right)$. Each profile in Fig. 5 represents the average value obtained for all dusty profiles detected in a $3^{\circ} \times 3^{\circ}$ grid box. A profile is classified as "dusty" if it is cloud-free and the VDR in any $2-\mathrm{km}$ altitude range (surface- $2 \mathrm{~km}, 2-4 \mathrm{~km}, 4-6 \mathrm{~km}$, $6-8 \mathrm{~km}$, or $8-10 \mathrm{~km}$ ) is greater than 0.06 . The ABR profiles shown in this figure have been corrected for molecular attenuation effects and ozone absorption. The plots shown in Fig. 5 provide some qualitative information on the dust concentrations, though the two parameters (ABR and VDR) are not linearly related to the dust concentration due to the presence of scattering signals from atmospheric molecules and also possibly from other types of aerosols (e.g., pollution in the industrial areas in India and eastern China). Attenuation due to the aerosol scattering in the upper atmosphere can also skew the ABR values computed for the lower atmosphere to values smaller than they otherwise would be. The VDR values are not perturbed by attenuation effects, because both the perpendicular and parallel components are attenuated identically, and thus the attenuation term cancels out when taking the ratio (refer to Eq. 2). Frequencies of dust occurrence and mean values of VDR for the five selected regions are given in Table 1.

Surrounding the TP there are several major dust sources, with the Taklimakan to the north, the Gobi deserts to the northeast, and deserts in Southwest Asia, including the Thar Desert, to the west and southwest. The Taklimakan and Gobi deserts in China (Qian et al., 2002) and the deserts on the Indian Subcontinent (Middleton, 1986) are very prolific dust sources, subordinate only to North Africa and the Arabian Peninsula (Prospero et al., 2002; Liu, D. et al., 2008). In these areas, the dust occurrences and spatial extents appear to have a similar seasonality, being most active in spring/summer and least active in winter. In spring, the spatial extent of airborne dusts is the largest. Vertically, a significant amount of dust is lifted up to 11-12 km (lower panels in Fig. 5). Horizontally, dust particles are carried for long distances into the Pacific Ocean or Arabian Sea (Fig. 4a). The transport of dusts is largely driven by atmospheric circulations. Due to its particular orography, the TP can modulate circulation generation and patterns over the area both dynamically and thermally (Wu et al., 2007; Liu et al., 2007). The mid-latitude westerly jet flow is thus split by the TP into two spiral branches, which influence the dust transport and distribution on the northern and southern sides.

Airborne dusts over the TP appear to be largely associated with meteorological activities on the northern side, being transported by the northern branch of the westerly flow from the Tarim Basin area and the Gobi deserts and from the Qaidam Basin on the plateau where the dust particles are typically mobilized by cold air outbreaks into free troposphere (Sun et al., 2001). The Gobi area, however, appears to contribute only to the TP airborne dust over the downwind northeastern TP (also refer to Fig. 7 in Sect. 3.4). The westerly flow tends to cause ascent on the upslope and descent on the downslope over the northern side of the TP (Liu et al., 2007). An "airborne dust corridor" is observed from west to east in China covering the northern slope and eastern part of the TP. This airborne dust corridor shows a seasonality driven largely by the prevailing atmospheric circulations: it extends southeastward, reaching southeastern China in spring, and northeastward in fall. In spring, very deep dust layers (over $1 \mathrm{~km}$, and up to $4 \mathrm{~km}$ over some locations) are seen over southeastern China. During this season, modulated by the TP, the northern branch of the westerly jet blows southeastward into eastern China, and can carry a large amount of dust particles from sources on the northern side of the TP and also possibly from the Loess Plateau into southeastern China. Meanwhile, the southern branch of the westerly jet blows northward over eastern China, resulting in spiral airflows when meeting the northern branch. The transported dust particles can be trapped by these spiral airflows within southeastern China for long periods of time. However, the optical depths of the airborne dust over southeastern China are normally smaller than those in the source regions. In summer and winter, the corridor lies nearly eastward. The airborne dust is largely confined to western and central North China in summer, and can be transported for long distances into the Pacific Ocean in spring and also in winter. The long range transport of Asian dust is a well known phenomenon in spring (e.g., Sun et al., 2001; Chun, et al., 2001; Uno et al., 2001; Murayama et al., 2001; Husar et al., 2001; Liu et al., 2002; Sassen, 2002). The occurrence of dust over the TP is the largest in spring over the northern slope and the eastern part (covering $\sim 1 / 3$ area in $4-6 \mathrm{~km}$ altitudes, $\sim$ half in $6-8 \mathrm{~km}$ altitudes) (Fig. 4). Dust particles can also be lifted high into the atmosphere $(\sim 12 \mathrm{~km})$ in this season (Fig. 5).

On the Indian Subcontinent, airborne desert dusts are mainly generated by sources in northwest India and Pakistan (Middleton, 1986) and can be transported for great distances by the southern branch of the westerly flow. Large dust storms are usually related to the eastward movement of a low-pressure zone or a trough, which can result in a steep pressure gradient and high winds that can last several days and produce dust storms over a wide area of northwest India 

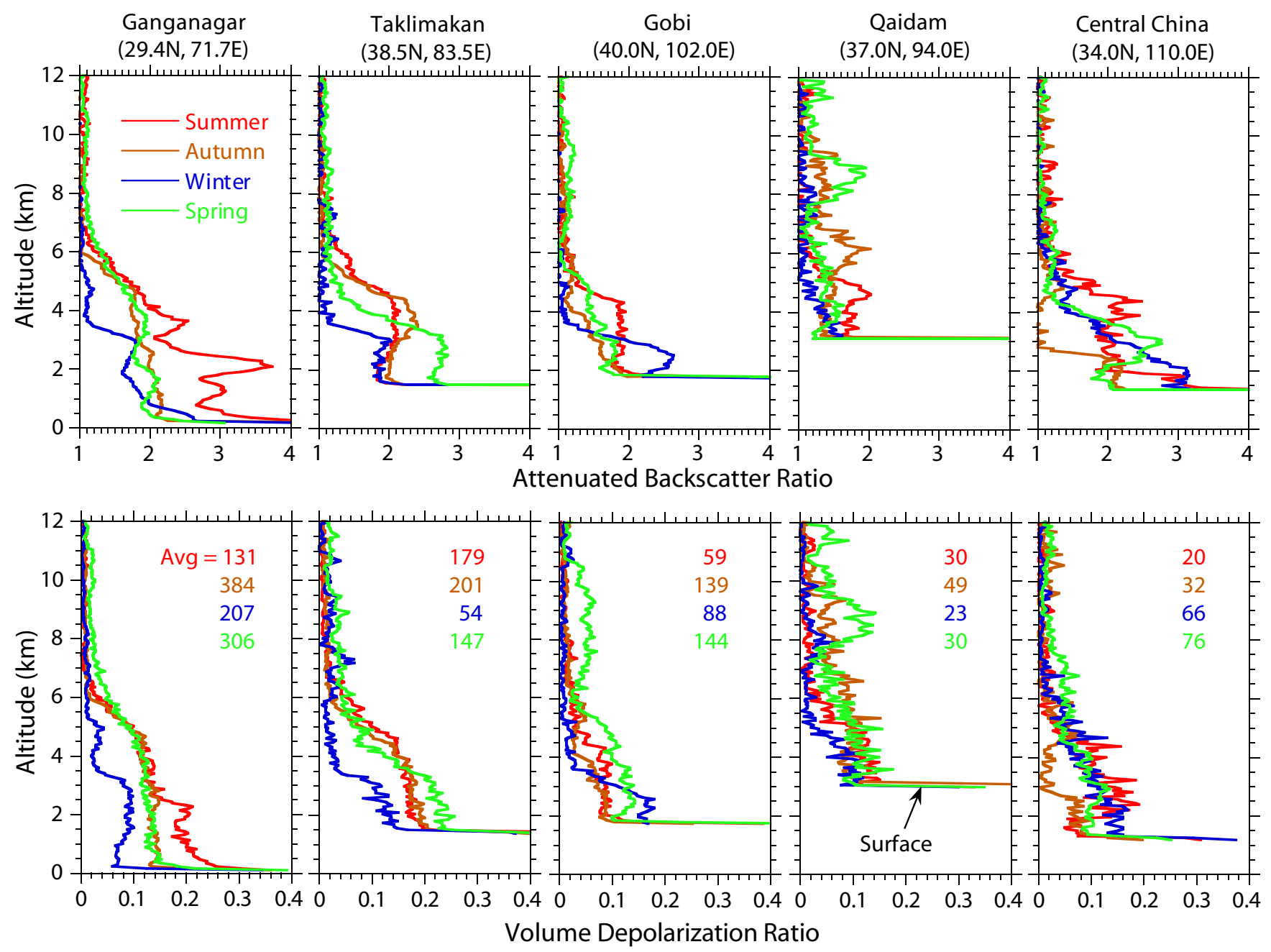

Fig. 5 Profiles of attenuated backscatter ratio (upper panels) and volume depolarization ratio (lower panels) for five selected locations respectively in the Ganganagar, Taklimakan and Gobi desert regions, the Qaidam Basin and southeastern China, averaged for dusty profiles in a $3^{\circ} \times 3^{\circ}$ box. A profile is classified as dusty if the VDR in any 2-km altitude range of it is greater than 0.06 . The numbers in each lower panel are the total number of dusty profiles that have been averaged, respectively, for summer, autumn, winter and spring. Variations are due partly to signal noise, depending on the number of samples averaged (the greater the number of samples, the smaller the noise-induced variation).

and Pakistan (Middleton, 1986). As seen in Fig. 4, dusts are transported across the entire subcontinent during springtime, with the dust occurrence frequency, from the surface to $4 \mathrm{~km}$, being greater than $80 \%$ on average for the whole area, and close to $100 \%$ for some locations in the source regions. Significant amounts of dust (occurrence frequency $>0.3$ ) are seen up to $7 \mathrm{~km}$ over the source regions (Figs. 4 and 5) and noticeable floating dusts are seen up to $11 \mathrm{~km}$ (Fig. 5). In the summer during the Indian monsoon season, very high frequencies (>90\%) (Fig. 4) are seen from the surface up to $6 \mathrm{~km}$ over the source regions in Pakistan and Afghanistan. That both ABR and VDR are the largest below $6 \mathrm{~km}$ (Fig. 5) may imply that the strength of dust emission in this season is the greatest. The seasonality observed by
CALIOP is in agreement with the ground station records of dust storms and dust hazes (Middleton, 1986) and with the TOMS measurement (Prospero et al., 2002). Unfortunately, using our current method, reliable dust occurrence statistics for central and southern India cannot be computed for the rainy season, as during this time the persistent cloud cover prohibits the acquisition of a sufficient quantity of cloud-free measurements (Fig. 4b). In wintertime the dust occurrence frequency reaches its minimum, and the dust occurrence is confined largely in lower altitudes and in the source regions in North India and Pakistan. However, dusts from the Indian Subcontinent do not appear to be transported significantly to the TP, as they are blocked by the Himalayas. The dust transport is orographically forced southeastward, around the 
Table 1. Airborne dust occurrence frequencies and volume depolarization ratios for five selected regions.

\begin{tabular}{|c|c|c|c|c|c|c|c|c|}
\hline \multirow{2}{*}{ Altitude range } & \multicolumn{2}{|c|}{ Summer } & \multicolumn{2}{|c|}{ Fall } & \multicolumn{2}{|c|}{ Winter } & \multicolumn{2}{|c|}{ Spring } \\
\hline & $f_{\text {occurrence }}$ & VDR & $f_{\text {occurrence }}$ & VDR & $f_{\text {occurrence }}$ & VDR & $f_{\text {occurrence }}$ & VDR \\
\hline \multicolumn{9}{|c|}{ Ganganagar (centered at $29.4^{\circ} \mathrm{N}, 71.7^{\circ} \mathrm{E}$ ) } \\
\hline $8-10 \mathrm{~km}$ & 0.00 & $\mathrm{NA}^{\mathrm{a}}$ & 0.00 & NA & 0.01 & 0.10 & 0.10 & 0.08 \\
\hline 6-8 km & 0.10 & 0.08 & 0.00 & NA & 0.01 & 0.16 & 0.15 & 0.07 \\
\hline $4-6 \mathrm{~km}$ & 0.92 & 0.11 & 0.40 & 0.13 & 0.15 & 0.10 & 0.64 & 0.10 \\
\hline $2-4 \mathrm{~km}$ & 1.00 & 0.15 & 0.72 & 0.13 & 0.67 & 0.09 & 0.98 & 0.12 \\
\hline $0-2 \mathrm{~km}$ & 1.00 & 0.21 & 0.78 & 0.13 & 0.63 & 0.09 & 1.00 & 0.12 \\
\hline \multicolumn{9}{|c|}{ Taklimakan $\left(38.5^{\circ} \mathrm{N}, 83.5^{\circ} \mathrm{E}\right)$} \\
\hline $8-10 \mathrm{~km}$ & 0.00 & $\mathrm{NA}$ & 0.03 & 0.10 & 0.00 & NA & 0.27 & 0.09 \\
\hline $6-8 \mathrm{~km}$ & 0.02 & 0.07 & 0.02 & 0.07 & 0.00 & NA & 0.32 & 0.09 \\
\hline $4-6 \mathrm{~km}$ & 0.88 & 0.13 & 0.70 & 0.11 & 0.00 & NA & 0.54 & 0.15 \\
\hline $2-4 \mathrm{~km}$ & 1.00 & 0.17 & 0.88 & 0.17 & 0.37 & 0.12 & 1.00 & 0.21 \\
\hline $0-2 \mathrm{~km}$ & 1.00 & 0.17 & 0.86 & 0.19 & 0.37 & 0.13 & 1.00 & 0.28 \\
\hline \multicolumn{9}{|c|}{ Gobi $\left(40.0^{\circ} \mathrm{N}, 102.0^{\circ} \mathrm{E}\right)$} \\
\hline $8-10 \mathrm{~km}$ & 0.05 & 0.07 & 0.01 & 0.07 & 0.02 & 0.07 & 0.06 & 0.07 \\
\hline $6-8 \mathrm{~km}$ & 0.03 & 0.07 & 0.02 & 0.07 & 0.04 & 0.09 & 0.02 & 0.06 \\
\hline $4-6 \mathrm{~km}$ & 0.35 & 0.08 & 0.06 & 0.08 & 0.05 & 0.10 & 0.25 & 0.15 \\
\hline $2-4 \mathrm{~km}$ & 0.65 & 0.10 & 0.64 & 0.08 & 0.28 & 0.11 & 0.43 & 0.15 \\
\hline $0-2 \mathrm{~km}$ & 0.65 & 0.10 & 0.58 & 0.08 & 0.24 & 0.14 & 0.41 & 0.14 \\
\hline \multicolumn{9}{|c|}{ Qaidam $\left(37.0^{\circ} \mathrm{N}, 94.0^{\circ} \mathrm{E}\right)$} \\
\hline $8-10 \mathrm{~km}$ & 0.01 & 0.06 & 0.02 & 0.10 & 0.04 & 0.08 & 0.49 & 0.15 \\
\hline $6-8 \mathrm{~km}$ & 0.05 & 0.11 & 0.10 & 0.11 & 0.02 & 0.11 & 0.63 & 0.11 \\
\hline $4-6 \mathrm{~km}$ & 0.75 & 0.12 & 0.30 & 0.16 & 0.14 & 0.08 & 0.78 & 0.14 \\
\hline $2-4 \mathrm{~km}$ & NA & NA & NA & NA & NA & NA & NA & NA \\
\hline $0-2 \mathrm{~km}$ & NA & NA & NA & NA & NA & NA & NA & NA \\
\hline \multicolumn{9}{|c|}{ Central China $\left(34.0^{\circ} \mathrm{N}, 110.0^{\circ} \mathrm{E}\right)$} \\
\hline $8-10 \mathrm{~km}$ & 0.00 & NA & 0.06 & 0.14 & 0.01 & 0.13 & 0.00 & NA \\
\hline $6-8 \mathrm{~km}$ & 0.00 & NA & 0.00 & NA & 0.00 & NA & 0.05 & 0.07 \\
\hline $4-6 \mathrm{~km}$ & 0.03 & 0.06 & 0.00 & NA & 0.02 & 0.09 & 0.20 & 0.08 \\
\hline $2-4 \mathrm{~km}$ & 0.16 & 0.10 & 0.71 & 0.07 & 0.46 & 0.17 & 0.90 & 0.10 \\
\hline $0-2 \mathrm{~km}$ & 0.16 & 0.09 & 1.00 & 0.10 & 0.54 & 0.13 & 1.00 & 0.13 \\
\hline
\end{tabular}

aNA: computations are not available for those altitude regions that lie below the Earth's surface, or for which no dusty profiles are identified by a depolarization ratio threshold of 0.06 .

southwestern slope of the Himalayas. This appears to be consistent with the simulated air flow pattern over this area $\mathrm{Wu}$ et al., 2007; Liu et al., 2007), and is confirmed by the season long HYSPLIT forward trajectory simulation presented in the next section.

To help to understand the CALIOP measured dust distributions, we provide a brief overview of other studies on the sources and mineral compositions of airborne dusts over the area. On the northern side, surfaces developed in or adjacent to piedmont alluvial fans of the mountains in northern and northwestern China and southern Mongolia, where there are persistent supplies of dust-sized alluvial deposits, are thought to be the major dust sources (Prospero, et al., 2001; Wang, et al., 2008). The Tarim Basin is typical of such regions: large alluvial fans slope toward the basin, and the basin floor is covered with a several hundred meters thick layer of alluvial deposits. In these source regions, fine fluvial/illuvial clay minerals and nano-sized calcite particles usually aggregate on and coat coarser grains in the source soils. Airborne dusts generated in these source regions consist mostly of aggregates of minerals. A recent study (Jeong, 2008) reported that the sandy soils in the desert source regions in North China consist mostly of quartz particles (44-63\%), along with other minerals such as plagioclase, K-feldspar, and phyllosilicate, 
etc. The quartz content is reduced in the silty soils of the Chinese loess and transported airborne dusts. The transported airborne dust commonly consists of clay aggregates (illite and interstratified illite-smectite), quartz particles, plagioclase, coarse calcite, and K-feldspar, etc. The total phyllosilicate content is increased (40-50\%), higher than the desert sands $(\sim 7 \%)$ and loess silts ( 23\%) (Jeong, 2008). Over the TP, an elemental composition analysis of ground-based samples has showed that the Tibetan dust aerosol contains more material of local origin than that transported from remote sources (Zhang, et al., 2001). The locally originating dusts are more similar to crustal material than to Chinese desert dust or dust from the Loess Plateau. On the Indian sub-continent, geochemical data suggest that sands in the Thar Desert, which occupies much of northwestern India and Pakistan, are alluvial materials, deposited by paleorivers draining the Himalayas. Extremely deep sediment deposits have been produced over time in the area. These alluvium sediment deposits and loess deposits, which derive from large-scale Pleistocene glaciofluvial outwash, may serve as the dust sources (Tripathi and Rajmani, 1999; Yadav and Rajamani, 2004). Coarser particles are largely related to a crustal origin (Yadav and Rajamani, 2004). Quartz is the dominant mineral, followed by K-feldspar, mica, calcite, chlorite and plagioclase, etc. Non-silicate crustal sources, atmospheric reaction products, and anthropogenic components, particularly products of biomass burning, constitute only minor amounts that are most noticeable in finer particles (Yadav and Rajamani, 2004).

The number distributions of cloud-free profiles that have been used in the analysis to derive the dust distributions are presented in Fig. 4b. It is seen that, except in some tropical and subtropical regions during summer (first panel in Fig. 4b), there are sufficient numbers of cloud-free profiles (20-200) to derive statistically reliable dust distributions.

\subsection{Comparisons with other measurements}

For comparisons, Fig. 6a, b and c present the seasonal distributions of the CALIOP dust occurrence frequency (surface to $10 \mathrm{~km}$ ), the mean aerosol index (AI) from the OMI measurements, and the mean aerosol optical thickness (AOT) derived by applying the Deep Blue algorithm to MODIS-Aqua measurements (Hsu et al., 2006), respectively. The OMI AI is a measure of how the wavelength dependence of UV radiation backscattered from an atmosphere containing aerosols differs from that expected from a purely molecular atmosphere. AI values are positive for absorbing aerosols (i.e., dust and pollution) and negative for non-absorbing aerosols (Torres et al., 1998). Therefore, the distributions shown in Fig. $6 \mathrm{~b}$ are representative of dust and pollution aerosols over the area. The MODIS Deep Blue algorithm takes advantage of the fact that deserts and semideserts have a weak surface bidirectional reflectance distribution functions for blue wavelengths to derive AOT estimates over the dust source regions
(Hsu et al., 2006). We note that the OMI and MODIS retrievals are only available for daytime measurements, while the CALIOP measurements analyzed in the study were made during nighttime.

As expected, these measurements show the largest degree of similarity in the aerosol distribution patterns over the source regions, such as the Tarim Basin area and the northwestern India and Pakistan, where dust is the dominant aerosol type. Differences in the distribution patterns are more prominent over those regions where different aerosol types exist simultaneously. For example, in central and East China different aerosol types frequently coexist, and in these regions large differences are seen in the aerosol distributions reported by the three instruments. In the summertime, the CALIOP measurements show very low dust occurrence frequencies (near zero) in Central and East China, while the OMI AI indicates the presence of a small to moderate amount of absorbing aerosols (the smallest AI values among the four seasons). Conversely, the MODIS Deep Blue AOT reaches its maximum in the central eastern China during the summer.

Some of the differences seen may be attributed to the different sensitivities and capabilities of each instrument. As mentioned earlier, CALIOP is highly sensitive to optically thin floating dusts that have horizontal visibilities over $60 \mathrm{~km}$ in the lower atmosphere, and even longer in the upper atmosphere. The CALIOP dust identification method is simple and straightforward. OMI and MODIS, on the other hand, cannot provide altitude-resolved measurements. For these instruments, accurate retrieval of aerosol properties depends on the aerosol vertical distribution, the elevation angle of the sun and the terrestrial surface type. Moreover, neither OMI nor MODIS can direct distinguish dust from other aerosol species.

It is interesting to note that, except for MODIS measurements in winter, both OMI and MODIS show that the Tarim Basin area is a more prolific source than the Gobi area. The CALIOP data (Table 1, Figs. 4 and 5) also show that the dust activity over the Tarim area is persistent almost all year long, which is similar to the observations made by OMI and MODIS. This phenomenon is likely due to the air circulations generated by the high mountains surrounding the basin, as these circulation patterns can create conditions favorable for keeping dust suspended aloft over the basin for extended periods of time (Tsunematsu et al., 2005). Over the Gobi area, on the other hand, a large portion of the fine particles in surface soils have been removed by Aeolian processes. What remains are primarily coarser particles that form a protective layer, and thus prevent the underlying fine material from being exposed to wind erosion (Wang et al., 2008). Consequently, the wind speeds required to initiate dust emissions are normally higher in the Gobi area $(\sim 7 \mathrm{~m} / \mathrm{s})$ than in the Tarim area $(\sim 4 \mathrm{~m} / \mathrm{s})$. Unlike the OMI and MODIS measurements, however, the CALIOP measurement reveals a frequency of dust occurrence over the Gobi area similar to that 

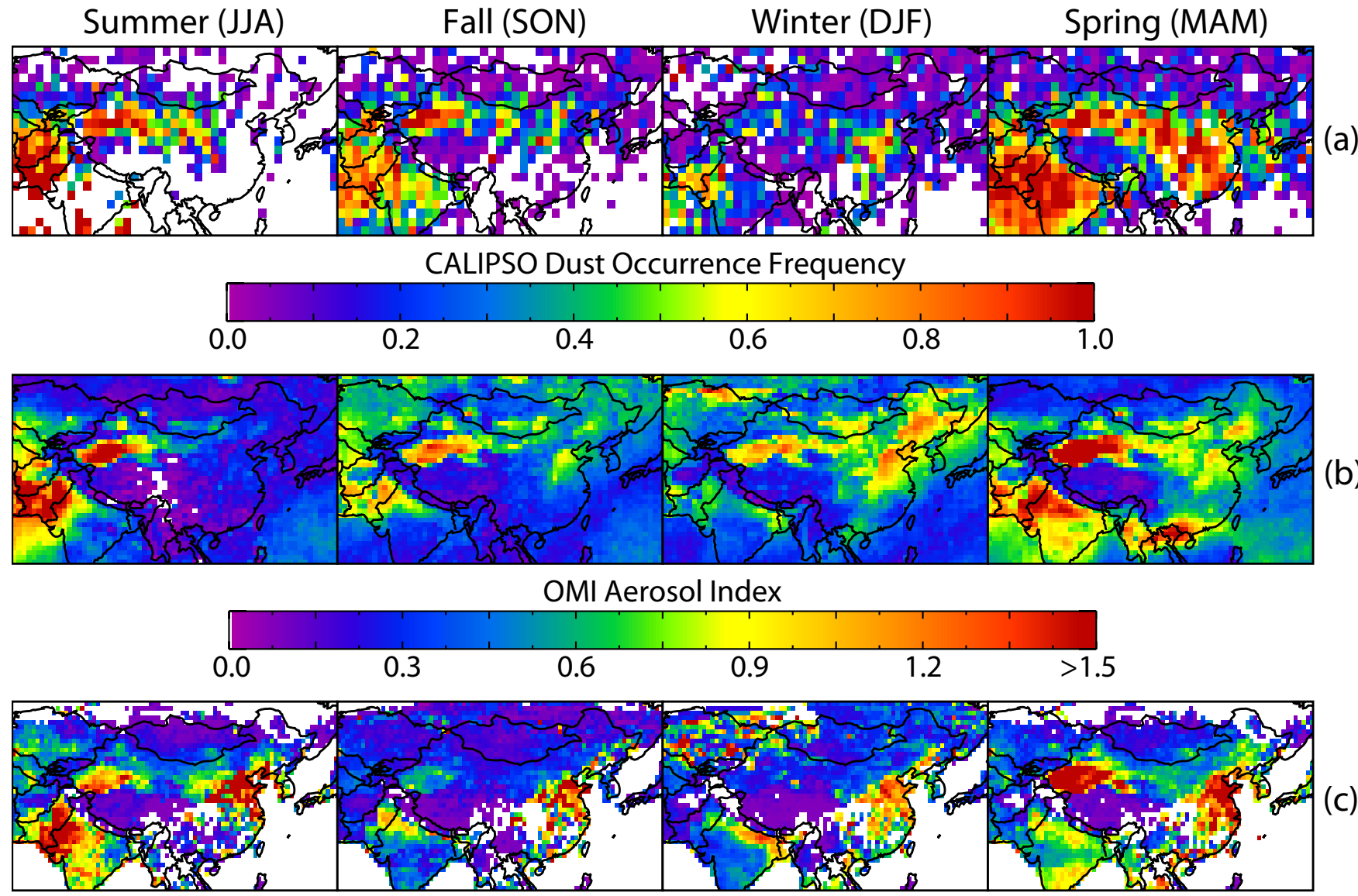

MODIS Deep Blue AOT

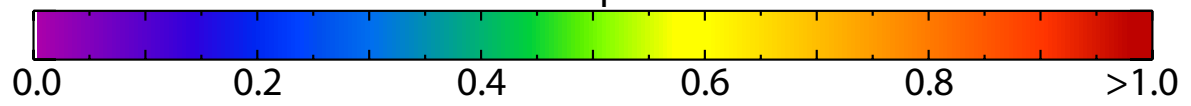

Fig. 6 (a) CALIOP dust occurrence frequency $\left(2^{\circ} \times 2^{\circ}\right)$ from the surface to $10 \mathrm{~km}$, (b) OMI aerosol index (AI) $\left(1.25^{\circ} \times 1^{\circ}\right)$, and $(\mathbf{c}) \mathrm{MODIS}$ Deep Blue aerosol optical thickness (AOT) $\left(1^{\circ} \times 1^{\circ}\right)$ derived from the Aqua measurements.

over the Tarim area in spring (Fig. 4a). This difference may be due to the different sensitivities of these instruments, as CALIOP can measure faint dust concentrations that lie below the detection thresholds of the passive sensors. The Gobi area also appears to contribute more to the transported dusts over the Central and East China than the Tarim area (also refer to Sect. 3.4) in the springtime.

\subsection{Seasonal HYSPLIT simulation}

To study the most likely transport routes of dusts emanating from the surrounding source regions and flowing into and across the TP, we conducted 20-day forward simulations using HYSPLIT. These simulations were conducted for the spring season, during which, as demonstrated in the previous section, the dust activity and transport is most significant. Three locations were selected: $38.5^{\circ} \mathrm{N}, 83.5^{\circ} \mathrm{E}$ in the Taklimakan in west China, $40.4^{\circ} \mathrm{N}, 102.0^{\circ} \mathrm{E}$ in the Gobi in central North China, and $29.4^{\circ} \mathrm{N}, 71.7^{\circ} \mathrm{E}$ in Ganganagar in Pakistan. The simulation was initiated at a height of $500 \mathrm{~m}$
(AGL) for each location, and repeated for every $6 \mathrm{~h}$ from 1 March through 31 May 2007. The results are presented in Fig. 7. The probability distribution for each air parcel is computed as the ratio of the number of trajectories passing through a given grid cell to the total number of 6-h runs. As is clearly shown in Fig. 7, dusts generated in both Tarim and Gobi areas can be transported to the TP and contribute to the observed "airborne dust corridor" in China. However, their contributions appear to be different; while the Tarim area appears to contribute to northern and eastern TP, the Gobi area appears to contribute only to the downwind northeastern TP. Significant amounts of dust can be carried to southeastern China in spring. Dust transport into and across the Pacific is also possible. On the other hand, the dusts mobilized on the Indian Subcontinent are transported mainly southeastward around the TP southwestern slope. After entering the tropical region, the transport at higher altitudes is changed to a southwestward direction by the tropical easterlies. However, at lower altitudes ( $0-2 \mathrm{~km} \mathrm{AGL)}$, almost no dust is seen to be 


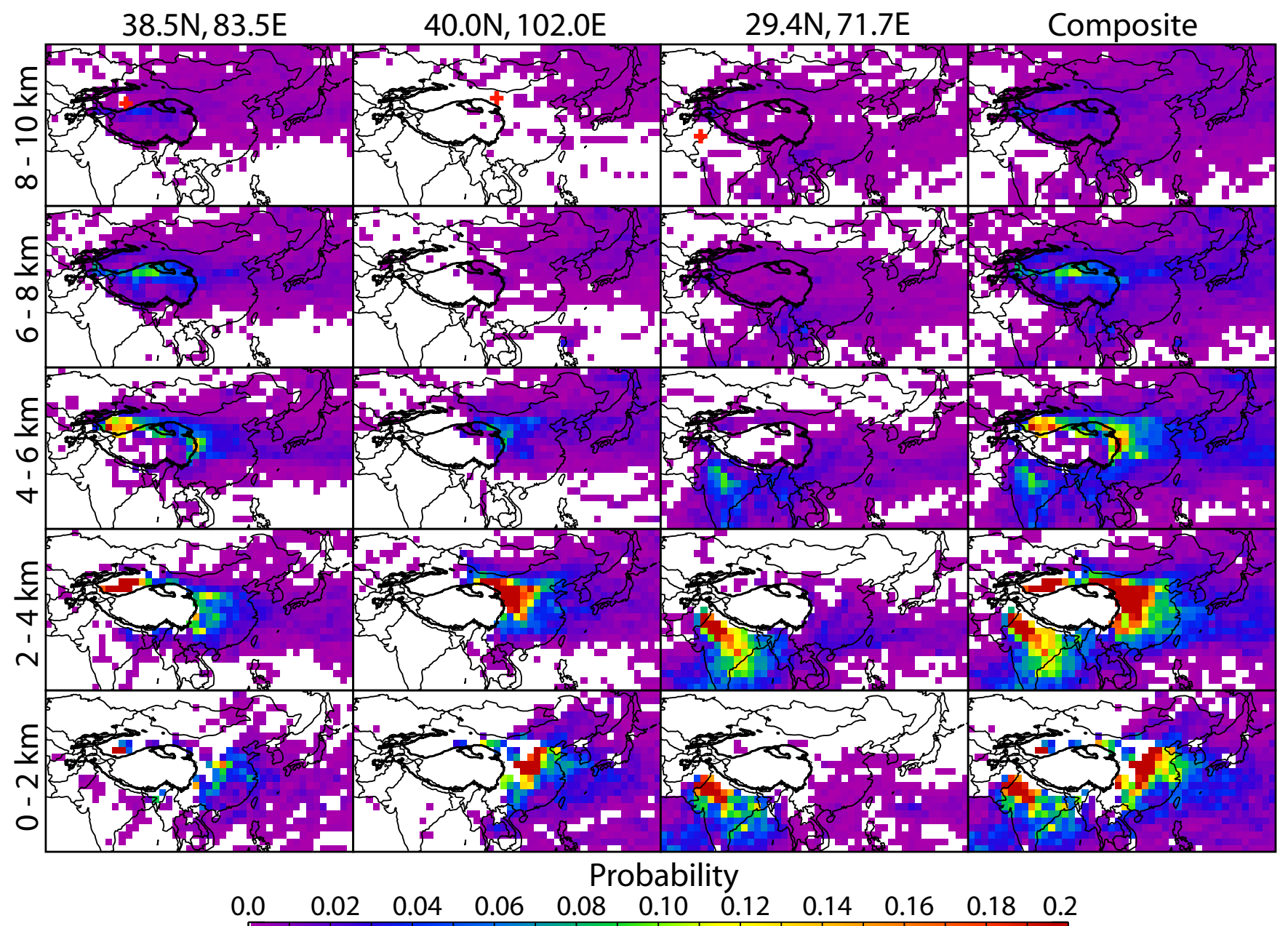

Fig. 7 Simulated dust distributions derived using the NOAA HYSPLIT model for the springtime months (March, April and May) of 2007, for three selected locations in the desert source regions $\left(38.5^{\circ} \mathrm{N}, 83.5^{\circ} \mathrm{E}\right.$ in Taklimakan in west China, $40.4^{\circ} \mathrm{N}, 102.0^{\circ} \mathrm{E}$ in $\mathrm{Gobi}$ in central north China, and $29.4^{\circ} \mathrm{N}, 71.7^{\circ} \mathrm{E}$ in Ganganagar in north India) indicated by the red cross symbols in the upper three panels, and four altitude ranges (AGL). The bold contour depicts the plateau where the elevation is larger than $3 \mathrm{~km}$. The pixel size is $2 \times 2$ degrees.

transported onto the western part of the TP, although some possibility of dust transport to the TP and the Pacific is shown at higher altitudes. In all three locations, the distribution patterns derived from the simulation study are strikingly similar to the observed dust distributions measured by CALIOP during the spring season of 2007 (i.e., as shown in Fig. 4).

We also conducted HYSPLIT simulations originating at a height of $1500 \mathrm{~m}$ (AGL). These results show a very similar transport pattern, although they are not presented in this paper.

\section{Summary}

In this paper, we use the first year of CALIPSO lidar measurements to derive an unprecedented set of altituderesolved, seasonally-dependent dust distributions over the Tibetan Plateau and the surrounding areas. The TP is sur- rounded by a number of prolific dust sources. Each year, large amounts of dust particles are mobilized from these sources and can be transported to and over the TP. This dust transport is primarily driven by atmospheric circulation. Due to its particular orography and location, the TP exerts significant influence on circulation generation and patterns, both dynamically and thermally, which in turn modulate the dust transport and distribution over the surrounding area. On the southern side, where circulation patterns are guided by the orography of the Himalayas (the highest mountain range in the world), the dusts generated in North India, Pakistan and/or Afghanistan are typically transported southeastward during the dry seasons. During springtime, large occurrence frequencies (close to 1 in many regions) are seen all over the Indian Subcontinent in the lower altitudes, from the surface to $\sim 4 \mathrm{~km}$. Airborne dusts are largely confined to Pakistan and Afghanistan during the summer monsoon season. 
However, the dusts are rarely, if ever, transported over the Himalayas to the TP.

On the northern side, large amounts of dust can be mobilized from the Tarim Basin and Gobi Desert areas by cold fronts and/or strong cyclone systems each year. Dusts can also be generated on the plateau (e.g., Qaidam Basin). An "airborne dust corridor" has been observed to regularly transport dust eastward, extending from the west to the east in China, covering the source regions, the northern slope and eastern part of the TP, Hexi Corridor, Loess Plateau and eastern China. This airborne dust corridor appears to be associated with dust activities in source regions both to the north of the TP and on the eastern TP. A clear seasonality is seen, and is considered to be largely driven by the atmospheric circulations. In spring, both the occurrence frequency and spatial coverage of the airborne dust reach maximums. During this time of year, the dust particles can be lofted to high altitudes, reaching $11-12 \mathrm{~km}$. The airborne dust corridor extends southeastward to southeastern China in spring and northeastward to the Northeastern Plain in fall. However, the airborne dust is confined largely to the source regions and to the northern slope and eastern part of the TP in summer. Comparing the two major sources in China (Table 1 and Fig. 4), the Tarim Basin area appears to be more prolific and persistent than the Gobi area except in winter. In the wintertime both attenuated backscatter ratio and volume depolarization ratio over the Gobi area are the largest in the lower troposphere (below $3 \mathrm{~km}$ ) and larger than that over the Taklimakan Desert area (Fig. 5). This may imply that the strength of the dust emission may be the strongest over the Gobi area during the wintertime of 2006/2007, though the occurrence frequency is the smallest in this season.

Comparisons of the CALIOP data with the OMI AI and MODIS Deep Blue AOT show, as expected, similarities in dust source regions. Away from the source regions, there are differences in both the spatial and seasonal distribution patterns reported by the three instruments. The HYSPLIT model was used to conduct a season long transport simulation for spring of 2006. Results of this simulation replicate the findings by CALIOP of the dust transport from the nearby sources. The Tarim Basin area appears to contribute to the TP airborne dust more than the Gobi area, while the Gobi area may contribute more to the airborne dust over Central and East China. In addition to the ubiquitous airborne dust, pollution aerosols and mixtures of pollution and dust were also commonly observed by CALIOP over the southern slope of the TP and a large area to the south.

The goal realized by this study is to provide a first step toward a better understanding of the Tibetan aerosols and their possible interaction with the climate. This study has also demonstrated that ground stations tend to miss some dust events (most especially lofted dust layers), and highlighted the utility of CALIOP measurements of airborne dust.

\section{Appendix A}

The visibility distance $V$ can be estimated from the atmospheric extinction coefficient, $\sigma$, Cohen, 1975) using

$V=3.912 / \sigma$.

Where

$\sigma=\sigma_{p}+\sigma_{m}=(R-1) S_{p} \sigma_{m} / S_{m}+\sigma m$,

$\sigma_{p}$ and $\sigma_{m}$ are the extinction coefficients, and $S_{p}$ and $S_{m}$ $(\approx 8 \pi / 3)$ are the lidar ratios, respectively, for particles and molecules. $R$ is the scattering ratio defined as the ratio of the total backscatter from both particles and molecules to the molecular-only backscatter. $R$ can be estimated from the volume depolarization ratio (VDR), $\delta_{V}$, the particulate depolarization ratio (PDR), $\delta_{P}$, and the molecular depolarization ratio $\left(\delta_{m}, \sim 0.0036\right.$ for CALIOP) using

$R=\frac{\left(1+\delta_{V}\right)\left(\delta_{P}-\delta_{m}\right)}{\left(\delta_{P}-\delta_{V}\right)\left(1+\delta_{m}\right)}$

(see, e.g., Cairo, et al., 1999). At $532 \mathrm{~nm}$ wavelength, $\sigma_{m} \approx 0.011 \mathrm{~km}^{-1}$ at $1 \mathrm{~km}$ altitude, and the lidar ratio and PDR for dusts range from $30-80 \mathrm{sr}$ and $20-40$ respectively, therefore, a threshold of 0.06 of the VDP corresponds to a horizontal visibility distance of $63-195 \mathrm{~km}$.

Edited by: R. MacKenzie

\section{References}

Barnett, T., Adam, J., and Lettenmaier, D.: Potential impacts of a warming climate on water availability in snow-dominated regions, Nature, 438, 303-309, 2005.

Cairo, F., Donfrancesco, G., Adriani, A., Pulvirenti, L., and Federico F.: Comparison of various linear depolarization parameters measured by lidar, Appl. Opt., 38, 4425-4432, 1999.

Cohen, A.: Horizontal visibility and the measurement of atmospheric optical depth of lidar, Appl. Opt., 14, 2878-2882, 1975.

Chun, Y. S., Boo, K. O., Kim, J., Park, S., and Lee, M.: Synopsis transport and physical characteristics of Asian dust in Korea, J. Geophys. Res., 106, 18 461-18 469, 2001.

Draxler, R. R. and Hess, G. D.: Description of the HYSPLIT_4 Modeling System, NOAA Technical Memorandum ERL ARL-224,online available at: http://www.arl.noaa.gov/data/web/ models/hysplit4/win95/arl-224.pdf, 2004.

Hess, M., Koepke, P., and Schult, I.: Optical properties of aerosols and clouds: The software package OPAC, Bull. Am. Meteorol. Soc., 79, 831-844, 1998. 
Hostetler, C., Liu, Z., Reagan, J., Vaughan, M., Winker, D., Osborn, M., Hunt, W., Powell, K., and Trepte, C.: CALIOP Algorithm Theoretical Basis Document - Part 1: Calibration and Level 1 Data Products, PC-SCI-201, Release 1.0, NASA Langley Research Center, Hampton, VA, USA, online available at: http://www-calipso.larc.nasa.gov/resources/ project_documentation.php, 2006.

Hsu, N., Tsay, S., King, M., and Herman, J.: Deep Blue retrievals of Asian aerosol properties during ACE-Asia, IEEE Trans. Geosci. Remote Sens., 44, 3180-3199, 2006.

Huang, J., Minnis, P., Yi, Y., Tang, Q., Wang, X., Hu, Y., Liu, Z., Ayers, K., Trepte, C., and Winker, D.: Summer dust aerosols detected from CALIPSO over the Tibetan Plateau, Geophys. Res. Lett., 34, L18805, doi:10.1029/2007GL029938, 2007.

Husar, R., Tratt, D., Schichtel, B., Falke, S., Li, F., Jaffe, D., Gasso, S., Gill, T., Laulainen, N., Lu, F., Reheis, M., Chun, Y., Westphal, D., Holben, B., Gueymard, C., McKendry, I., Kuring, N., Feldman, G., McClain, C., Frouin, R., Merrill, J., DuBois, D., Vignola, F., Murayama, T., Nickovic, S., Wilson, W., Sassen, K., Sugimoto, N., and Malm, W.: Asian dust events of April 1998, J. Geophys. Res., 106, 18 317-18 330, 2001.

Jeong, G. Y.: Bulk and single-particle mineralogy of Asian dust and a comparison with its source soils, J. Geophys. Res., 113, D02208, doi:10.1029/2007JD008606, 2008.

Kobayashi, A., Hayashida S., Okada, K., and Iwasaka, Y.: Measurements of the polarization properties of Kosa (Asian dust-storm) particles by a laser radar in spring 1983, J. Meteorol. Soc. Japan., 63, 144-149, 1983.

Kurosaki, Y. and Mikami, M.: Threshold wind speed for dust emission in east Asia and its seasonal variations, J. Geophys. Res., 112, D17202, doi:10.1029/2006JD007988, 2007.

Lau, K., Kim, M., and Kim, K.: Asian summer monsoon anomalies induced by aerosol direct forcing: the role of the Tibetan Plateau, Clim. Dynam., 26(7-8), 855-864, doi:10.1007/s00382006-0114-z, 2006.

Liu, D., Wang, Z., Liu, Z., Winker, D., and Trepte, C.: A height resolved global view of dust aerosols from the first year CALIPSO lidar measurements, J. Geophys. Res., in press, 2008.

Liu, X. and Chen, B.: Climatic warming in the Tibetan Plateau during recent decades, Int. J. Climatol., 20, 1729-1742, 2000.

Liu, Y., Hoskins, B., and Blackburn, M.: Impact of Tibetan orography and heating on the summer flow over Asia, J. Meteor. Soc. Jpn., 85B, 1-19, 2007.

Liu, Z., Omar, A., Vaughan, M., Hair, J., Kittaka, C., Hu, Y., Powell, K., Trepte, C., Winker, D., Hostetler, C., Ferrare, R., and Pierce, B.: CALIPSO lidar observations of optical properties of Saharan dust: A case study of long range transport, J. Geophys. Res., 113, D07207, doi:10.1029/2007JD008878, 2007.

Liu, Z., Vaughan, M., Winker, D., Hostetler, C., Poole, L., Hlavka, D., Hart, W., and McGill, M.: Use of probability distribution functions for discriminating between cloud and aerosol in lidar backscatter data, J. Geophys. Res., 109, D15202, doi:10.1029/2004JD004732, 2004.

Liu, Z., Sugimoto, N., and Murayama, T.: Extinction-to-backscatter ratio of Asian dust observed by high-spectral-resolution lidar and Raman lidar, Appl. Opt., 41, 2760-2767, 2002.

McNeil, W. and Carswell, A.: Lidar polarization studies of the troposphere, Appl. Opt., 14, 2158-2168, 1975.
Middleton, N.: A geography of dust storms in south-west Asia, J. Climatol., 6, 183-196, 1986.

Murayama, T., Sugimoto, N., Uno, I., Kinoshita, K., Aoki, K., Hagiwara, N., Liu, Z., Matsui, I., Sakai, T., Shibata, T., Arao, K., Shon, B.-J., Won, J.-G., Yoon, S.-C., Li, T., Zhou, J., Hu, H., Abo, M., Iokibe, K., Koga, R., and Iwasaka, Y.: Ground-based network observation of Asian dust events of April 1998 in east Asia, J. Geophys. Res., 106(D16), 18 345-18 360, 2001.

Prospero, J. M., Ginoux, P., Torres, O., Nicholson, S. E., and Gill, T. E.: Environmental characterization of global sources of atmospheric soil dust identified with the NIMBUS 7 Total Ozone Mapping Spectrometer (TOMS) absorbing aerosol product, Rev. Geophys., 40(1), 1002, doi:10.1029/2000RG000095, 2002.

Pueschel, R. F. and Livingston, J. M.: Aerosol spectral optical depths: Jet fuel and forest fire smokes, J. Geophys. Res., 95, 22 417-22 422, 1990.

Qian, W., Quan, L., and Shi, S.: Variations of the dust storm in China and its climatic control, J. Climate, 15, 1216-1229, 2002.

Ramanathan, V., Ramana, M., Roberts, G., Kim, D., Corrigan, C., Chung, C., and Winker, D.: Warming trends in Asia amplified by brown cloud solar absorption, Nature, 448, 575-578, 2007.

Sassen, K.: Indirect climate forcing over the western US from Asian dust storms, Geophys. Res. Lett., 29(10), 1465, doi:10.1029/2001GL014051, 2002.

Seinfeld, J., Carmichael, G., Arimoto, R., Conant, W., Brechtel, F., Bates, T., Cahill, T., Clarke, A., Doherty, S., Flatau, P., Huebert, B., Kim, J., Markowicz, K., Quinn, P., Russell, L., Russell, P., Shimizu, A., Shinozuka, Y., Song, C., Tang, Y., Uno, I., Vogelmann, A., Weber, R., Woo, J., and Zhang, X.: ACE-ASIA regional climatic and atmospheric chemical effects of Asian dust and pollution, Bull. Am. Meteorol. Soc., 85, 367-380, 2004.

Shao, Y. and Dong, C.: A review on East Asian dust storm climate, modeling and monitoring, Global Planet. Change, 52, 122, 2006.

Sun J., Zhang, M., and Liu, T.: Spatial and temporal characteristics of dust storms in China and its surrounding regions, 19601999: Relations to source area and climate, J. Geophys. Res., 106(D10), 10325-10333, 2001.

Thompson, L., Mosley-Thompson, E., Davis, M., Lin, P., Henderson, K., and Mashiotta, T.: Tropical glacier and ice core evidence of climate change on annual to millennial time scales, Clim. Change, 59, 137-155, 2003.

Torres, O., Bhartiea, P., Herman, J., Ahmad, Z., and Gleason, J.: Derivation of aerosol properties from satellite measurements of backscattered ultraviolet radiation: Theoretical basis, J. Geophys. Res., 103, D14, 17 099-17 110, 1998.

Tripathi, J. K. and Rajamani, V.: Geochemistry of the loessic sediments on Delhi ridge, eastern Thar desert, Rajasthan: Its implication to exogenic processes, Chem. Geol., 155, 265-278, 1999.

Tsunematsu, N., Kai, K., and Matsumoto, T.: The Influence of Synoptic-scale Air Flow and Local Circulation on the Dust Layer Height in the North of the Taklimakan Desert, Water Air Soil. Poll.: Focus 5, 175-193, 2005.

Uno, I., Amano, H., Emori, S., Kinoshita, K., Matsui, I., and Sugimoto, N.: Trans-Pacific yellow sand transport observed in April 1998: A numerical simulation, J. Geophys. Res., 106(D16), 18331-18 344, doi:10.1029/2000JD900748, 2001. 
Uno, I., Harada, K., Satake, S., Hara, Y., and Wang, Z.: Meteorological characteristics and dust distribution of the Tarim Basin simulated by the nesting RAMS/CFORS dust model, J. Meteor. Soc. Jpn., 83A, 219-239, 2005.

Vaughan, M., Young, S., Winker, D., Powell, K., Omar, A., Liu, Z., Hu, Y., and Hostetler, C.: Fully automated analysis of spacebased lidar data: an overview of the CALIPSO retrieval algorithms and data products, Proc. SPIE, 5575, 16-30, 2004.

Wang, X., Xia, D., Wang, T., Xue, X., and Li, J.: Dust sources in arid and semiarid China and southern Mongolica: Impacts of geomorphological setting and surface materials, Geomorphology, 97, 583-600, 2008.

Winker, D., Hunt, W., and McGill, M.: Initial performance assessment of CALIOP, Geophys. Res. Lett., 34, L19803, doi:10.1029/2007GL030135, 2007.
Wu, G., Liu, Y., Wang, T., Wan, R., Liu, X., Li, W., Wang, Z., Zhang, Q., Duan, A., and Liang, X.: Influence of dynamical and thermal forcing by the Tibetan Plateau on Asian climate, J. Hydrometeorol., 8, 770-789, 2007.

Yadav, S. and Rajamani, V.: Geochemistry of aerosols of northwestern part of India adjoining the Thar desert, Geochim Cosmochim Ac., 68, 1975-1988, 2004.

Zhang, X. Y., Arimoto, R., Cao, J. J., An, Z. S., and Wang, D.: Atmospheric dust aerosol over the Tibetan Plateau, J. Geophys. Res., 106(D16), 18 471-18 476, 2001.

Zuberi, B., Bertram, A., Cassa, C., Molina, L., and Molina, M.: Heterogeneous nucleation of ice in $\left(\mathrm{NH}_{4}\right) 2 \mathrm{SO}_{4}-\mathrm{H}_{2} \mathrm{O}$ particles with mineral dust immersions, Geophys. Res. Lett., 29(10), 1504, doi:10.1029/2001GL014289, 2002. 